UDC 519.61:519.62:621.372.82

DOI: $10.22363 / 2658-4670-2020-28-4-361-377$

\title{
Single-mode propagation of adiabatic guided modes in smoothly irregular integral optical waveguides
}

\author{
Anton L. Sevastianov \\ Peoples' Friendship University of Russia (RUDN University) \\ 6, Miklukho-Maklaya St., Moscow, 117198, Russian Federation
}

(received: June 10, 2020; accepted: November 12, 2020)

This paper investigates the waveguide propagation of polarized electromagnetic radiation in a thin-film integral optical waveguide. To describe this propagation, the adiabatic approximation of solutions of Maxwell's equations is used. The construction of a reduced model for adiabatic waveguide modes that retains all the properties of the corresponding approximate solutions of the Maxwell system of equations was carried out by the author in a previous publication in DCM \& ACS, 2020, No 3. In this work, for a special case when the geometry of the waveguide and the electromagnetic field are invariant in the transverse direction. In this case, there are separate nontrivial TE- and TM-polarized solutions of this reduced model. The paper describes the parametrically dependent on longitudinal coordinates solutions of problems for eigenvalues and eigenfunctions - adiabatic waveguide TE and TM polarizations. In this work, we present a statement of the problem of finding solutions to the model of adiabatic waveguide modes that describe the stationary propagation of electromagnetic radiation. The paper presents solutions for the single-mode propagation of TE and TM polarized adiabatic waveguide waves.

Key words and phrases: waveguide propagation of polarized light, integral optical waveguide, adiabatic approximation, eigenvalues and eigenfunctions, Kantorovich method, single-mode regime

\section{Introduction}

In works [1]-[5] a cycle of studies of the propagation of polarized light in integrated-optical smoothly irregular thin-film waveguides was carried out within the framework of the model of adiabatic waveguide waves. They showed the advantages of the model and its advantages over other models in the description of open dielectric waveguides [6]-[8]. At the same time, until recently, the question of substantiating this model remained open. In work [9] the substantiation of the model was carried out, which is a reduction of a more complex in use general model based on Maxwell's equations. In the present work, within the framework of the model of adiabatic waveguide waves, the problem of stationary propagation of polarized light in a smoothly irregular

(C) Sevastianov A.L., 2020

This work is licensed under a Creative Commons Attribution 4.0 International License

http://creativecommons.org/licenses/by/4.0/ 
integral-optical waveguide is posed, an auxiliary problem for eigenvalues and eigenfunctions (adiabatic waveguide modes) is formulated and solved. The solution of the stationary problem by the generalized Kantorovich method is proposed, its solution is obtained in the single-mode propagation mode.

\section{Basic concepts and notation}

Waveguide propagation of monochromatic polarized electromagnetic radiation in integrated optical waveguides is described by Maxwell's equations. The electromagnetic field is described using complex amplitudes. The material environment is considered, consisting of dielectric subdomains that fill the entire three-dimensional space. The latter means that the dielectric constants of the subdomains are different and real, and the magnetic permeability is everywhere equal to the magnetic permeability of the vacuum. It follows from the foregoing that in the absence of external currents and charges, the induced currents and charges are equal to zero.

In the absence of external charges and currents, the scalar Maxwell equations follow from the vector ones, and the boundary conditions for the normal components follow from the boundary conditions for the tangential components. The constitutive equations of connection in the case under consideration are assumed to be linear. Thus, the electromagnetic field in a space filled with dielectrics in the Gaussian system of units is described by the equations [10]:

$$
\operatorname{rot} \mathbf{E}=-\frac{1}{c} \frac{\partial \mathbf{B}}{\partial t}, \quad \operatorname{rot} \mathbf{H}=-\frac{1}{c} \frac{\partial \mathbf{D}}{\partial t}, \quad \mathbf{D}=\varepsilon \mathbf{E}, \quad \mathbf{B}=\mu \mathbf{H},
$$

where $\mathbf{E}, \mathbf{H}$ are the vectors of electric and magnetic field strength; $\mathbf{D}$ is the electric displacement vector, $\mathbf{B}$ is the magnetic flux density vector; $c$ is the velocity of electromagnetic wave propagation in vacuum.

In this case, the boundary conditions

$$
\left.\mathbf{H}_{\tau}\right|_{1}=\left.\mathbf{H}_{\tau}\right|_{2},\left.\quad \mathbf{E}_{\tau}\right|_{1}=\left.\mathbf{E}_{\tau}\right|_{2} .
$$

and the asymptotic boundary conditions at infinity

$$
\|\mathbf{E}\| \underset{|x| \rightarrow \infty}{\longrightarrow} 0, \quad\|\mathbf{H}\| \underset{|x| \rightarrow \infty}{\longrightarrow} 0,
$$

are assumed to hold for guided modes, which ensures the uniqueness of the solution to problem (1)-(2).

In equations (1): $\varepsilon$ is the permittivity of the medium; $\mu$ is the permeability of the medium, $\mathbf{E}, \mathbf{H}$ are the electric and magnetic field strength vectors. We denote by $n=\sqrt{\mu \varepsilon}$ the refractive index of the medium (here and below - of a layer of the multilayer dielectric structure under consideration).

All subdomains are infinite and bonded by planes parallel to the $y O z$-plane and surfaces, asymptotically parallel to the $y O z$-plane, so that below we have $\varepsilon=\varepsilon(x), \mu=1$. 


\section{Model of adiabatic guided modes}

In Ref. [9] the adiabatic approximation of the guided solution of Maxwell's equations is found in the form:

$$
\left\{\begin{array}{l}
\vec{E}(x, y, z, t) \\
\vec{H}(x, y, z, t)
\end{array}\right\}=\left\{\begin{array}{l}
\vec{E}_{0}(x ; y, z) \\
\vec{H}_{0}(x ; y, z)
\end{array}\right\} \exp \left\{i \omega t-i k_{0} \varphi(y, z)\right\}
$$

where

$$
\begin{gathered}
\varepsilon \frac{\partial E_{0}^{y}}{\partial x}=-i k_{0}\left(\frac{\partial \varphi}{\partial y}\right)\left(\frac{\partial \varphi}{\partial z}\right) H_{0}^{y}-i k_{0}\left(\varepsilon \mu-\left(\frac{\partial \varphi}{\partial y}\right)^{2}\right) H_{0}^{z} \\
\varepsilon \frac{\partial E_{0}^{z}}{\partial x}=i k_{0}\left(\varepsilon \mu-\left(\frac{\partial \varphi}{\partial z}\right)^{2}\right) H_{0}^{y}+i k_{0}\left(\frac{\partial \varphi}{\partial z}\right)\left(\frac{\partial \varphi}{\partial y}\right) H_{0}^{z} \\
\mu \frac{\partial H_{0}^{y}}{\partial x}=i k_{0}\left(\frac{\partial \varphi}{\partial y}\right)\left(\frac{\partial \varphi}{\partial z}\right) E_{0}^{y}+i k_{0}\left(\varepsilon \mu-\left(\frac{\partial \varphi}{\partial y}\right)^{2}\right) E_{0}^{z} \\
\mu \frac{\partial H_{0}^{z}}{\partial x}=-i k_{0}\left(\varepsilon \mu-\left(\frac{\partial \varphi}{\partial z}\right)^{2}\right) E_{0}^{y}-i k_{0}\left(\frac{\partial \varphi}{\partial z}\right)\left(\frac{\partial \varphi}{\partial y}\right) E_{0}^{z} \\
E_{0}^{x}=-\frac{\partial \varphi}{\partial y} \frac{1}{\varepsilon} H_{0}^{z}+\frac{\partial \varphi}{\partial z} \frac{1}{\varepsilon} H_{0}^{y}, \quad H_{0}^{x}=\frac{\partial \varphi}{\partial y} \frac{1}{\mu} E_{0}^{z}-\frac{\partial \varphi}{\partial z} \frac{1}{\mu} E_{0}^{y}
\end{gathered}
$$

After additional differentiations from four first-order ODEs, four secondorder ODEs are obtained, two of which take the form:

$$
\begin{aligned}
& \frac{\partial^{2} E_{0}^{y}}{\partial x^{2}}+k_{0}^{2}\left(\varepsilon \mu-\left(\frac{\partial \varphi}{\partial y}\right)^{2}-\left(\frac{\partial \varphi}{\partial z}\right)^{2}\right) E_{0}^{y}=0, \\
& \frac{\partial^{2} H_{0}^{y}}{\partial x^{2}}+k_{0}^{2}\left(\varepsilon \mu-\left(\frac{\partial \varphi}{\partial y}\right)^{2}-\left(\frac{\partial \varphi}{\partial z}\right)^{2}\right) H_{0}^{y}=0 .
\end{aligned}
$$

in the case when the layers (three or four) of a multilayer waveguide are homogeneous.

The rest four components are calculated from the system of linear algebraic equations (SLAE)

$$
\begin{aligned}
i k_{0} \varepsilon E_{0}^{x}+i k_{0} \frac{\partial \varphi}{\partial y} H_{0}^{z}=i k_{0} \frac{\partial \varphi}{\partial z} H_{0}^{y}, & i k_{0} \varepsilon E_{0}^{z}-i k_{0} \frac{\partial \varphi}{\partial y} H_{0}^{x}=\frac{\partial H_{0}^{y}}{\partial x} \\
i k_{0} \frac{\partial \varphi}{\partial y} E_{0}^{z}-i k_{0} \mu H_{0}^{x}=i k_{0} \frac{\partial \varphi}{\partial z} E_{0}^{y}, & -i k_{0} \mu H_{0}^{z}-i k_{0} \frac{\partial \varphi}{\partial y} E_{0}^{z}=\frac{\partial E_{0}^{y}}{\partial x}
\end{aligned}
$$




\section{Waveguides regular in $y$ and electromagnetic fields}

First, let us consider the case when neither the integrated optical waveguide geometry, nor the solutions to Maxwell's equations for the adiabatic guided mode (AGM) depend on one of the horizontal coordinates, i.e., the case $\partial / \partial y \equiv 0$.

For fields harmonic in time in the Cartesian system of coordinates, the system of Maxwell's equations has the form:

$$
\begin{cases}\frac{\partial H_{z}}{\partial y}-\frac{\partial H_{y}}{\partial z}=i k_{0} \varepsilon E_{x}, & \frac{\partial E_{z}}{\partial y}-\frac{\partial E_{y}}{\partial z}=-i k_{0} \mu H_{x} \\ \frac{\partial H_{x}}{\partial z}-\frac{\partial H_{z}}{\partial x}=i k_{0} \varepsilon E_{y}, & \frac{\partial E_{x}}{\partial z}-\frac{\partial E_{z}}{\partial x}=-i k_{0} \mu H_{y} \\ \frac{\partial H_{y}}{\partial x}-\frac{\partial H_{x}}{\partial y}=i k_{0} \varepsilon E_{z}, & \frac{\partial E_{y}}{\partial x}-\frac{\partial E_{x}}{\partial y}=-i k_{0} \mu H_{z}\end{cases}
$$

In the case $\partial / \partial y \equiv 0$, system (8) takes the form

$$
\left\{\begin{array}{l}
-\frac{\partial H_{y}}{\partial z}=i k_{0} \varepsilon E_{x}, \quad-\frac{\partial E_{y}}{\partial z}=-i k_{0} \mu H_{x} \\
\frac{\partial E_{x}}{\partial z}-\frac{\partial E_{z}}{\partial x}=-i k_{0} \mu H_{y}, \quad \frac{\partial H_{x}}{\partial z}-\frac{\partial H_{z}}{\partial x}=i k_{0} \varepsilon E_{y} \\
\frac{\partial H_{y}}{\partial x}=i k_{0} \varepsilon E_{z}, \quad \frac{\partial E_{y}}{\partial x}=-i k_{0} \mu H_{z}
\end{array}\right.
$$

A substitution of the first and the third equations (9) into the second ones leads to the equivalent systems

$$
\left\{\begin{array}{l}
\frac{\partial^{2} E_{y}}{\partial z^{2}}+\frac{\partial^{2} E_{y}}{\partial x^{2}}+k_{0}^{2} \varepsilon \mu E_{y}=0 \\
-\frac{\partial E_{y}}{\partial z}=-i k_{0} \mu H_{x} \\
\frac{\partial E_{y}}{\partial x}=-i k_{0} \mu H_{z}
\end{array}\right.
$$

for TE polarization and

$$
\left\{\begin{array}{l}
\frac{\partial^{2} H_{y}}{\partial z^{2}}+\frac{\partial^{2} H_{y}}{\partial x^{2}}+k_{0}^{2} \varepsilon \mu H_{y}=0 \\
-\frac{\partial H_{y}}{\partial z}=i k_{0} \varepsilon E_{x} \\
\frac{\partial H_{y}}{\partial x}=i k_{0} \varepsilon E_{z}
\end{array}\right.
$$

for TM polarization. 
In this case, the system of equations (6), (7) is split into two independent subsystems:

for TE polarization:

$$
\left\{\begin{array}{l}
\frac{d^{2} E_{0}^{y}}{d x^{2}}+k_{0}^{2}\left(\varepsilon \mu-\left(\frac{d \varphi}{d z}\right)^{2}\right) E_{0}^{y}=0 \\
\mu H_{0}^{x}=-\frac{d \varphi}{d z} E_{0}^{y} \\
-i k_{0} \mu H_{0}^{z}=\frac{d E_{0}^{y}}{d x}
\end{array}\right.
$$

and for TM polarization:

$$
\left\{\begin{array}{l}
\frac{d^{2} H_{0}^{y}}{d x^{2}}+k_{0}^{2}\left(\varepsilon \mu-\left(\frac{d \varphi}{d z}\right)^{2}\right) H_{0}^{y}=0, \\
i k_{0} \varepsilon E_{0}^{z}=\frac{d H_{0}^{y}}{d x} \\
\varepsilon E_{0}^{x}=\frac{d \varphi}{d z} H_{0}^{y} .
\end{array}\right.
$$

For thin film multilayer waveguide consisting of optically homogeneous layers, the system of equations (12) and (13) should be completed with the conditions of the electromagnetic field matching at the interfaces between the media that follow from $(2)$ :

$$
\begin{aligned}
& \vec{n} \times \vec{E}^{-}+\vec{n} \times \vec{E}^{+}=0, \\
& \vec{n} \times \vec{H}^{-}+\vec{n} \times \vec{H}^{+}=0
\end{aligned}
$$

and the asymptotic conditions that follow from (3):

$$
E_{y}^{0}, E_{z}^{0}, H_{y}^{0}, H_{z}^{0} \underset{x \rightarrow \pm \infty}{\longrightarrow} 0 .
$$

\section{Setting of the physical problem}

The solution of the first equation of system (10) is found using the generalized Kantorovich method [11], [12], which is analogous to the method of separation of variables proposed in [13]. We find the solutions to an auxiliary problem analogous to a problem of finding eigenvalues and eigenfunctions that depend on a parameter.

Auxiliary eigenvalue problem

For each fixed $z$ we consider the problem

$$
\left(\frac{d^{2}}{d x^{2}}+k_{0}^{2} n^{2}(x, z)\right) E_{y}^{j}(x ; z)=k_{0}^{2} \beta_{j}^{2}(z) E_{y}^{j}(x ; z), \quad-\infty<x<\infty,
$$


where $\beta(z)=\frac{d \varphi}{d z}(z)$, with the boundary (asymptotic) conditions

$$
E_{y}^{j}(x ; z) \underset{x \rightarrow \pm \infty}{\longrightarrow} 0 .
$$

Let us normalize the eigenfunctions with a condition

$$
\left\langle E_{y}^{j}, E_{y}^{k}\right\rangle=\int_{-\infty}^{\infty} E_{y}^{j}(x ; z) \bar{E}_{y}^{k}(x ; z) d x=\delta_{j k} .
$$

It is known that for any fixed $z \in \mathbb{R}$ problem (17)-(19) is a problem of finding normal guided TE modes of a regular planar reference waveguide [14], [15]. At any real-valued $\varepsilon, \mu$ and any finite thickness of the reference waveguide it allows a finite number $N^{\mathrm{TE}}$ of forward and $N^{\mathrm{TE}}$ of backward TE modes [16][18].

We restrict ourselves to considering such smoothly irregular waveguides in which the number of guided modes is constant throughout the change and the degree of irregularity is so small that the transformation of the energy of guided modes is limited by the adiabatic approximation. In this case, we seek a solution to problem in the form of an expansion:

$$
E_{y}^{0}(x, z)=\sum_{-N^{\mathrm{TE}}}^{N^{\mathrm{TE}}} C_{j}^{\mathrm{TE}}(z) E_{y}^{j}(x ; z),
$$

satisfying the condition

$$
\frac{\partial E_{y}^{0}}{\partial z}(x, z)=-i \sum_{-N^{\mathrm{TE}}}^{N^{\mathrm{TE}}} k_{0} \beta_{j}^{\mathrm{TE}}(z) C_{j}^{\mathrm{TE}}(z) E_{y}^{j}(x ; z) .
$$

Substituting expansion (20),(21) into Eqs. (10) with relations (19) taken into account, after cumbersome but not complicated transformations, we arrive at a system of ODEs for the expansion coefficient functions $C_{j}^{\mathrm{TE}}(z)$.

\section{Solution of a single-mode problem for zero contribution to the AGM}

As an example, let us carry out the above calculations for the particular case (20), (21), which describes the single-mode propagation of a TE-polarized AGM, namely:

$$
\tilde{E}_{y}^{j}(x, z)=C_{j}^{\mathrm{TE}}(z) E_{y}^{j}(x ; z),
$$

satisfying condition

$$
\frac{\partial \tilde{E}_{y}^{j}}{\partial z}(x, z)=-i k_{0} \beta_{j}^{\mathrm{TE}}(z) C_{j}^{\mathrm{TE}}(z) E_{y}^{j}(x ; z) .
$$


We differentiate (23) with respect to $z$ and substitute the result into the first equation of the system (10) taking into account (17) (following [13]). As a result, we arrive at a system consisting of a single ODE

$$
\frac{d C_{j}^{\mathrm{TE}}}{d z}(z) \beta_{j}^{\mathrm{TE}}(z)+\frac{d \beta_{j}^{\mathrm{TE}}}{d z}(z) C_{j}^{\mathrm{TE}}(z)=0 .
$$

We substitute the solution of Eq. (24) into relation (22) and obtain the ultimate explicit form of the component $\tilde{E}_{y}^{j}$ of the electromagnetic field of the single-mode TE polarized AGM:

$$
\tilde{E}_{y}^{j}(x, z)=\frac{\beta_{j}^{\mathrm{TE}}(0)}{C_{j}^{\mathrm{TE}}(0)} \frac{E_{y}^{j}(x ; z)}{\beta_{j}^{\mathrm{TE}}(z)} .
$$

By means of the second equation of the system (10) we obtain

$$
\tilde{H}_{z}^{j}(x, z)=-\frac{1}{i k_{0} \mu} \frac{d \tilde{E}_{y}^{j}}{d x}(x, z)
$$

and using the third equation of the system (10) we obtain

$$
\tilde{H}_{x}^{j}(x, z)=\frac{\beta_{j}^{\mathrm{TE}}(z)}{\mu} \tilde{E}_{y}^{j}(x, z) .
$$

In analogy with the above calculations, we solve the system (11) using the auxiliary problem

$$
\left(\frac{d^{2}}{d x^{2}}+k_{0}^{2} n^{2}(x, z)\right) H_{y}^{j}(x ; z)=k_{0}^{2} \beta_{j}^{2}(z) H_{y}^{j}(x ; z), \quad-\infty<x<\infty,
$$

with boundary (asymptotic) conditions

$$
H_{y}^{j}(x ; z) \underset{x \rightarrow \pm \infty}{\longrightarrow} 0 .
$$

The eigenfunctions are normalized by the condition

$$
\left\langle H_{y}^{j}, H_{y}^{k}\right\rangle=\int_{-\infty}^{\infty} H_{y}^{j}(x ; z) \bar{H}_{y}^{k}(x ; z) d x=\delta_{j k} .
$$

The single-mode solution for the TM-polarized AGM has the form

$$
\begin{gathered}
\tilde{H}_{y}^{j}(x, z)=\frac{\beta_{j}^{\mathrm{TM}}(0)}{C_{j}^{\mathrm{TM}}(0)} \frac{H_{y}^{j}(x ; z)}{\beta_{j}^{\mathrm{TM}}(z)}, \\
\tilde{E}_{z}^{j}(x, z)=\frac{1}{i k_{0} \varepsilon} \frac{d \tilde{H}_{y}^{j}}{d x}(x, z)
\end{gathered}
$$




$$
\tilde{E}_{x}^{j}(x, z)=-\frac{\beta_{j}^{\mathrm{TM}}(z)}{\varepsilon} \tilde{H}_{y}^{j}(x, z) .
$$

\section{Search for adiabatic guided mode phase using the Cauchy method}

In the model of adiabatic guided modes, in addition to the coefficient functions $C_{j}^{\mathrm{TE}}(z)$ and $C_{j}^{\mathrm{TM}}(z)$, the explicit dependence on the horizontal coordinate is present in the exponential factor $\exp \left\{i \omega t-i k_{0} \varphi(y, z)\right\}$ in expression (4) [9]. The mode evolution in the horizontal direction, besides the dependences (24) for the coefficient functions in the case $\partial / \partial y \equiv 0$, is formed by the dependence of $d \varphi / d z$ on the obtained eigenvalues of problems (17). It is convenient to formulate the description of phase evolution law $\varphi(z)$ in terms of the algebraic model of adiabatic guided modes [9] for thin-film waveguides. A constructive representation of this dependence for thin-film waveguides consisting of homogeneous layers is obtained in Refs. [19]-[21]. Namely, the general solutions in the homogeneous layers have the form

$$
\begin{gathered}
\left(\begin{array}{c}
E_{y}^{s} \\
H_{z}^{s} \\
H_{y}^{s} \\
E_{z}^{s}
\end{array}\right)=\left(\begin{array}{c}
-i \mu_{s} \exp \left\{k_{0} \eta_{s}^{j}(z) x\right\} A_{s}^{1} \\
\eta_{s}^{j}(z) \exp \left\{k_{0} \eta_{s}^{j}(z) x\right\} A_{s}^{1} \\
i \varepsilon_{s} \exp \left\{k_{0} \eta_{s}^{j}(z) x\right\} A_{s}^{2} \\
\eta_{s}^{j}(z) \exp \left\{k_{0} \eta_{s}^{j}(z) x\right\} A_{s}^{2}
\end{array}\right), \\
\left(\begin{array}{c}
E_{y}^{f} \\
H_{z}^{f} \\
H_{y}^{f} \\
E_{z}^{f}
\end{array}\right)=\left(\begin{array}{c}
i \mu_{f}\left(\exp \left\{-k_{0} \eta_{f}^{j}(z) x\right\} A_{f}^{3}-\exp \left\{-k_{0} \eta_{f}^{j}(z) x\right\} A_{f}^{1}\right) \\
\eta_{f}^{j}(z)\left(\exp \left\{-k_{0} \eta_{f}^{j}(z) x\right\} A_{f}^{3}+\exp \left\{-k_{0} \eta_{f}^{j}(z) x\right\} A_{f}^{1}\right) \\
i \varepsilon_{f}\left(\exp \left\{-k_{0} \eta_{f}^{j}(z) x\right\} A_{f}^{2}-\exp \left\{-k_{0} \eta_{f}^{j}(z) x\right\} A_{f}^{4}\right) \\
\eta_{f}^{j}(z)\left(\exp \left\{-k_{0} \eta_{f}^{j}(z) x\right\} A_{f}^{4}+\exp \left\{-k_{0} \eta_{f}^{j}(z) x\right\} A_{f}^{2}\right)
\end{array}\right), \\
\left(\begin{array}{c}
E_{y}^{c} \\
H_{z}^{c} \\
H_{y}^{c} \\
E_{z}^{c}
\end{array}\right)=\left(\begin{array}{c}
i \mu_{c} \exp \left\{k_{0} \eta_{c}^{j}(z)(-x+h)\right\} A_{c}^{3} \\
\eta_{c}^{j}(z) \exp \left\{k_{0} \eta_{c}^{j}(z)(-x+h)\right\} A_{c}^{3} \\
-i \varepsilon_{c} \exp \left\{k_{0} \eta_{c}^{j}(z)(-x+h)\right\} A_{c}^{4} \\
\eta_{c}^{j}(z) \exp \left\{k_{0} \eta_{c}^{j}(z)(-x+h)\right\} A_{c}^{4}
\end{array}\right),
\end{gathered}
$$

where $\eta_{\alpha}^{j}(z)=\sqrt{\beta_{j}^{2}(z)-n_{\alpha}^{2}}, \alpha=s, f, c$.

The system of boundary Maxwell's equations (2) with the explicit form of solutions (34),(36) taken into account leads [22]-[24] to the systems of homogeneous linear algebraic equations

$$
\hat{M}^{\mathrm{TE}}\left(A_{s}^{1} A_{f}^{1} A_{f}^{3} A_{f}^{3}\right)^{T}=\left(\begin{array}{llll}
0 & 0 & 0 & 0
\end{array}\right)^{T}
$$


for TE modes, where

$$
\hat{M}^{\mathrm{TE}}=\left(\begin{array}{cccc}
i \mu_{c} & i \mu_{f} \exp \left\{k_{0} \eta_{f}^{j}(z) h\right\} & -i \mu_{f} \exp \left\{-k_{0} \eta_{f}^{j}(z) h\right\} & 0 \\
0 & i \mu_{f} & -i \mu_{f} & -i \mu_{s} \\
0 & -\eta_{f}^{j}(z) & -\eta_{f}^{j}(z) & \eta_{s}^{j}(z) \\
\eta_{c}^{j}(z) & -\eta_{f}^{j}(z) \exp \left\{k_{0} \eta_{f}^{j}(z) h\right\} & -\eta_{f}^{j}(z) \exp \left\{-k_{0} \eta_{f}^{j}(z) h\right\} & 0
\end{array}\right)
$$

and

$$
\hat{M}^{\mathrm{TM}}\left(A_{s}^{2} A_{f}^{2} A_{f}^{4} A_{c}^{4}\right)^{T}=\left(\begin{array}{llll}
0 & 0 & 0 & 0
\end{array}\right)^{T}
$$

for TM modes, where

$$
\hat{M}^{\mathrm{TM}}=\left(\begin{array}{cccc}
0 & -i \varepsilon_{f} & i \varepsilon_{f} & i \varepsilon_{s} \\
i \varepsilon_{s} & -i \varepsilon_{f} \exp \left\{k_{0} \eta_{f}^{j}(z) h\right\} & i \varepsilon_{f} \exp \left\{-k_{0} \eta_{f}^{j}(z) h\right\} & 0 \\
\eta_{c}^{j}(z) & -\eta_{f}^{j}(z) \exp \left\{k_{0} \eta_{f}^{j}(z) h\right\} & -\eta_{f}^{j}(z) \exp \left\{-k_{0} \eta_{f}^{j}(z) h\right\} & 0 \\
0 & -\eta_{f}^{j}(z) & -\eta_{f}^{j}(z) & \eta_{s}^{j}(z)
\end{array}\right) .
$$

The systems of homogeneous linear algebraic equations (37) and (39) have nontrivial solutions under the conditions

$$
\begin{aligned}
& \operatorname{det} \hat{M}^{\mathrm{TE}}\left(d \varphi^{\mathrm{TE}} / d z\right)=0, \\
& \operatorname{det} \hat{M}^{\mathrm{TM}}\left(d \varphi^{\mathrm{TM}} / d z\right)=0
\end{aligned}
$$

In terms of ordinary differential equations for $d \varphi^{\mathrm{TE}} / d z$ and $d \varphi^{\mathrm{TM}} / d z$, equations (41) and (42) are written in the form

$$
F\left(\frac{d \varphi}{d z}(z) ; h(z), \frac{d h}{d z}(z) ; \varepsilon_{\alpha}, \mu_{\alpha}\right)=0,
$$

where $F$ is a transcendental function of $\frac{d \varphi}{d z}$, including expressions $\eta_{\alpha}^{j}(z)=$ $\sqrt{\beta_{j}^{2}(z)-n_{\alpha}^{2}}, \alpha=s, f, c$ and $\exp \left\{ \pm k_{0} \eta_{\alpha}^{j}(z) h(z)\right\}, \alpha=s, f, c$ i.e., radicals of $\left(\frac{d \varphi}{d z}\right)^{2}$ and exponential functions of these radicals.

Equations (41) and (42) of the form (43) are solved symbolic-numerically using the Cauchy method (see [25], [26]).

\section{Basic equations of the adiabatic guided mode model}

The problem of propagation of polarized electromagnetic radiation in regular waveguides was successfully solved both in closed [27]-[30] and in open waveguides [31]. In both cases the base method is the method of separation of variables, which reduces the initial problem to an auxiliary 
spectral problem with a discrete spectrum in the case of closed waveguides and a mixed spectrum in the case of open ones.

Problems with dielectric and magnetic filling of waveguides, intricate in the cross section but regular in the longitudinal direction (along the radiation propagation axis) were reduced to considerably more complicated spectral problems, which have been subsequently also solved (see, e.g., [32]-[39]). These physical models gave rise to new mathematical problems and description of new electromagnetic phenomena, which are beyond the present discussion.

In contrast to this line of study, the mathematical modeling of waveguides irregular in the longitudinal direction began to develop from the middle of the 20th century. Here we should mention the pioneering works [40]-[42] in the English-language literature. However, the dominant contribution to the development of mathematically substantiated methods was made by Russianlanguage authors. Their works can be conventionally divided into congeneric, in fact, to the ideology of Kantorovich method [43] generalizing the Fourier method of separation of variables (e.g., [44]-[54]) and those using the ideology of asymptotic approach (see, e.g., [55]). It is worth noting that the studies in the first line have acquired rigorous mathematical completeness in the works by Sveshnikov and his disciples (see, e.g., [56]-[66]).

The present paper combines the Sveshnikov ideas in both approaches and bases on technique of exploiting the Kantorovich method, implicitly used by Fedoryuk.

\section{Acknowledgments}

The publication has been prepared with the support of the Russian Foundation for Basic Research (RFBR) according to the research project No 19-01-00645. The author is grateful to his colleague Dmitry Divakov for providing the results of computer calculations.

\section{References}

[1] L. A. Sevastianov and A. A. Egorov, "Theoretical analysis of the waveguide propagation of electromagnetic waves in dielectric smoothlyirregular integrated structures," Optics and Spectroscopy, vol. 105, no. 4, pp. 576-584, 2008. DOI: 10.1134/S0030400X08100123.

[2] A. A. Egorov and L. A. Sevastianov, "Structure of modes of a smoothly irregular integrated optical four-layer three-dimensional waveguide," Quantum Electronics, vol. 39, no. 6, pp. 566-574, 2009. DOI: 10.1070/ QE2009v039n06ABEH013966.

[3] A. A. Egorov, K. P. Lovetskiy, A. L. Sevastianov, and L. A. Sevastianov, "Simulation of guided modes (eigenmodes) and synthesis of a thin-film generalised waveguide Luneburg lens in the zero-order vector approximation," Quantum Electronics, vol. 40, no. 9, pp. 830-836, 2010. DoI: 10.1070/QE2010V040N09ABEH014332. 
[4] A. A. Egorov et al., "Adiabatic modes of smoothly irregular optical waveguide: zero approximation of vector theory [Adiabaticheskie mody plavno-neregulyarnogo opticheskogo volnovoda: nulevoe priblizhenie vektornoj teorii]," Russian, Matem. modelirovaniye, vol. 22, no. 8, pp. 4254, 2010, [in Russian].

[5] A. A. Egorov, A. L. Sevast'yanov, and L. A. Sevast'yanov, "Stable computer modeling of thin-film generalized waveguide Luneburg lens," Quantum Electronics, vol. 44, no. 2, pp. 167-173, 2014. DOI: 10.1070/ QE2014v044n02ABEH015303.

[6] A. A. Egorov, K. P. Lovetsky, A. L. Sevastyanov, and L. A. Sevastyanov, "Luneberg Thin-Film Waveguide Lens: From Problem Statement to Solution. Theory and mathematical modeling of adiabatic modes [Tonkoplenochnaya volnovodnaya linza Lyuneberga: ot postanovki problemy do ee resheniya. Teoriya i matematicheskoe modelirovanie adiabaticheskih mod]," Russian, in Trudy RNTORES im. A.S. Popova. Vyp. 5. The 5th International Conference "Acousto-Optical and Radar Measurement and Information Processing Methods" (ARMIMP-2012), Moscow-Suzdal, [in Russian], 2012, pp. 186-190.

[7] A. A. Egorov, A. L. Sevastyanov, E. A. Ayryan, and L. A. Sevastyanov, "Stable computer modeling of thin-film generalized waveguide Luneburg lens [Ustojchivoe komp'yuternoe modelirovanie tonkoplenochnoj obobshchennoj volnovodnoj linzy Lyuneberga|," Russian, Matem. modelirovaniye, vol. 26, no. 11, pp. 37-44, 2014, [in Russian].

[8] E. Ayryan, G. Dashitsyrenov, E. Laneev, K. Lovetskiy, L. Sevastianov, and A. Sevastianov, "Mathematical synthesis of the thickness profile of the waveguide Lüneburg lens using the adiabatic waveguide modes method," in Saratov Fall Meeting 2016: Laser Physics and Photonics XVII; and Computational Biophysics and Analysis of Biomedical Data III, V. L. Derbov, D. E. Postnov, V. L. Derbov, and D. E. Postnov, Eds., International Society for Optics and Photonics, vol. 10337, SPIE, 2017, pp. 134-145. DOI: 10.1117/12.2267920.

[9] A. L. Sevastyanov, "Asymptotic method for constructing a model of adiabatic guided modes of smoothly irregular integrated optical waveguides," Discrete and Continuous Models and Applied Computational Science, vol. 28 , no. 3, pp. 252-273, 2020. DOI: 10.22363/2658-46702020-28-3-252-273.

[10] A. S. Il'inskii, V. V. Kravtsov, and A. G. Sveshnikov, Mathematical Models of Electrodynamics [Matematicheskie modeli elektrodinamiki], Russian. Moscow: Vyssh. Shkola, 1991, [in Russian].

[11] L. A. Sevastyanov, A. A. Egorov, and A. L. Sevastyanov, "Method of adiabatic modes in studying problems of smoothly irregular open waveguide structures," Physics of Atomic Nuclei, vol. 776, no. 2, pp. 224 239, 2013. DOI: 10.1134/S1063778813010134.

[12] L. V. Kantorovich and V. I. Krylov, Approximate Methods of Higher Analysis. New York: Wiley, 1964. 
[13] M. V. Fedoryuk, "A justification of the method of transverse sections for an acoustic wave guide with nonhomogeneous content," Mathematical Physics, vol. 13, no. 1, pp. 162-173, 1973. DOI: 10.1016/0041-5553(74) 90012-3.

[14] B. Z. Katsenelenbaum, Theory of Irregular Waveguides with Slowly Varying Parameters /Teoriya neregulyarnyh volnovodov s medlenno menyayushchimisya parametramil, Russian. Moscow: Akad. Nauk SSSR, 1961, [in Russian].

[15] V. V. Shevchenko, Continuous Transitions in Open Waveguides [Plavnye perekhody v otkrytyh volnovodah], Russian. Moscow: Nauka, 1969, [in Russian].

[16] M. J. Adams, An Introduction to Optical Waveguides. New York: Wiley, 1981.

[17] T. Tamir, "Guided-wave optoelectronics," in Integrated Optics, T. Tamir, Ed., Berlin: Springer-Verlag, 1990.

[18] A. W. Snyder and J. D. Love, Optical Waveguide Theory. New York: Chapman and Hall, 1983.

[19] D. V. Divakov and A. L. Sevastianov, "The Implementation of the Symbolic-Numerical Method for Finding the Adiabatic Waveguide Modes of Integrated Optical Waveguides in CAS Maple," in Computer Algebra in Scientific Computing, M. England, W. Koepf, T. M. Sadykov, W. M. Seiler, and E. V. Vorozhtsov, Eds., Cham: Springer International Publishing, 2019, pp. 107-121. DOI: 10.1007/978-3-030-26831-2\_8.

[20] D. V. Divakov, A. A. Tiutiunnik, and A. L. Sevastianov, "SymbolicNumeric Study of Geometric Properties of Adiabatic Waveguide Modes," in Computer Algebra in Scientific Computing, F. Boulier, M. England, T. M. Sadykov, and E. V. Vorozhtsov, Eds., Cham: Springer International Publishing, 2020, pp. 228-244. DOI: 10.1007/978-3-030-60026$6 \backslash \_13$.

[21] D. V. Divakov and A. A. Tiutiunnik, "Symbolic study of eigenvectors for constructing a general solution to a system of ODEs with a symbolic matrix of coefficients," Programmirovaniye, no. 2, pp. 3-16, 2020.

[22] L. A. Sevastyanov, A. L. Sevastyanov, and A. A. Tyutyunnik, "Analytical Calculations in Maple to Implement the Method of Adiabatic Modes for Modelling Smoothly Irregular Integrated Optical Waveguide Structures," in Computer Algebra in Scientific Computing, V. P. Gerdt, W. Koepf, W. M. Seiler, and E. V. Vorozhtsov, Eds., Cham: Springer International Publishing, 2014, pp. 419-431. DOI: 10.1007/978-3-319-10515-4\_30.

[23] A. A. Egorov, K. P. Lovetskii, A. L. Sevastianov, and L. A. Sevastianov, Integrated optics: theory and computer modeling [Integral'naya optika: teoriya i komp'yuternoe modelirovanie], Russian. Moscow: PFUR Publishing house, 2015, [in Russian]. 
[24] A. A. Egorov, K. P. Lovetskii, A. L. Sevastyanov, and L. A. Sevastyanov, "Model of a smoothly irregular multilayer integrated-optical waveguide in the zero vector approximation: theory and numerical analysis [Model' mnogoslojnogo plavno-neregulyarnogo integral'no-opticheskogo volnovoda v nulevom vektornom priblizhenii: teoriya i chislennyj analiz]," Russian, Zhurnal radioelektroniki, no. 3, 2019, [in Russian]. DOI: 10 . 30898/1684-1719.2019.3.11.

[25] M. D. Malykh, "On integration of the first order differential equations in a finite terms," Journal of Physics: Conference Series, vol. 788, p. 012026 , Jan. 2017. DOI: 10.1088/1742-6596/788/1/012026.

[26] A. D. Polyanin and V. E. Nazaikinskii, Handbook of linear partial differentialequations for engineers and scientists, 2nd Edition. BocaRaton, London: CRC Press, 2016.

[27] A. A. Samarskiy and A. N. Tikhonov, "Excitation of radio waveguides. I [O vozbuzhdenii radiovolnovodov. I ]," Russian, Zhurnal tekhnicheskoy fiziki, vol. 17, no. 11, pp. 1283-1296, 1947, [in Russian].

[28] A. A. Samarskiy and A. N. Tikhonov, "Excitation of radio waveguides. II [O vozbuzhdenii radiovolnovodov. II ]," Russian, Zhurnal tekhnicheskoy fiziki, vol. 17, no. 12, pp. 1431-1440, 1947, [in Russian].

[29] A. A. Samarskiy and A. N. Tikhonov, "Excitation of radio waveguides. III [O vozbuzhdenii radiovolnovodov. III ]," Russian, Zhurnal tekhnicheskoy fiziki, vol. 18, no. 7, pp. 971-983, 1948, [in Russian].

[30] A. A. Samarskii and A. N. Tikhonov, "Representation of the field in a waveguide as the sum of the TE and TM fields [O predstavlenii polya v volnovode v vide summy polej TE i TM]," Russian, Zhurnal tekhnicheskoy fiziki, vol. 18, no. 7, pp. 959-970, 1948, [in Russian].

[31] V. V. Shevchenko, "Spectral decomposition in eigen- and associated functions of a nonselfadjoint problem of Sturm-Liouville type on the entire axis [O spektral'nom razlozhenii po sobstvennym i prisoedinennym funkciyam odnoj nesamosopryazhennoj zadachi tipa Shturma-Liuvillya na vsej osi]," Russian, Differ. Uravn., vol. 15, no. 11, pp. 2004-2020, 1979, [in Russian].

[32] E. M. Karchevskii, "Determination of the propagation constants of dielectric-waveguide eigenmodes by methods of potential theory," Computational Mathematics and Mathematical Physics, vol. 38, no. 1, pp. 132136, 1998.

[33] R. Z. Dautov and E. M. Karchevskii, "On a spectral problem of the theory of dielectric waveguides," Computational Mathematics and Mathematical Physics, vol. 39, no. 8, pp. 1293-1299, 1999.

[34] E. M. Karchevskii, "Analysis of the eigenmode spectra of dielectric waveguides," Computational Mathematics and Mathematical Physics, vol. 39, no. 9, pp. 1493-1498, 1999.

[35] E. M. Karchevskii, "Investigation of a numerical method for solving a spectral problem in the theory of dielectric waveguides," Russian Mathematics (Izvestiya VUZ. Matematika), vol. 43, no. 1, pp. 8-15, 1999. 
[36] R. Z. Dautov and E. M. Karchevskii, "Existence and properties of solutions to the spectral problem of the dielectric waveguide theory," Computational Mathematics and Mathematical Physics, vol. 40, no. 8, pp. 1200-1213, 2000.

[37] R. Z. Dautov and E. M. Karchevskii, "Solution of the vector problem of the natural waves of cylindrical dielectric waveguides based on a nonlocal boundary condition," Computational Mathematics and Mathematical Physics, vol. 42, no. 7, pp. 1012-1027, 2002.

[38] E. M. Karchevskii and S. I. Solov'ev, "Existence of eigenvalues of a spectral problem in the theory of dielectric waveguides," Russian Mathematics (Izvestiya VUZ. Matematika), vol. 47, no. 3, pp. 75-77, 2003.

[39] E. M. Karchevskii, A. I. Nosich, and G. W. Hanson, "Mathematical analysis of the generalized natural modes of an inhomogeneous optical fiber," SIAM Journal on Applied Mathematics, vol. 65, no. 6, pp. 20332048, 2005. DOI: 10.1137/040604376.

[40] A. F. Stevenson, "General Theory of Electromagnetic Horns," Journal of Applied Physics, vol. 22, no. 12, p. 1447, 1951. DOI: 10.1063/1.1699891.

[41] S. A. Schelkunoff, "Conversion of Maxwell's equations into generalized Telegraphist's equations," The Bell System Technical Journal, vol. 34, no. 5, pp. 995-1043, 1955. DOI: 10.1002/j.1538-7305.1955.tb03787. $\mathrm{x}$.

[42] A. Yariv, "Coupled-mode theory for guided-wave optics," IEEE Journal of Quantum Electronics, vol. 9, pp. 919-933, 1973. DOI: 10.1109/JQE. 1973.1077767.

[43] L. V. Kantorovich, "A direct method for the approximate solution of the problem of the minimum of a double integral [Odin pryamoj metod priblizhennogo resheniya zadachi o minimume dvojnogo integralal," Russian, Izvestiya Akademii nauk SSSR. VII seriya. Otdeleniye matematicheskikh $i$ yestestvennykh nauk, no. 5, pp. 647-652, 1933, [in Russian].

[44] B. Z. Katsenelenbaum, "Irregular waveguides with slowly varying parameters [Neregulyarnye volnovody s medlenno menyayushchimisya parametrami]," Russian, Doklady Akademii Nauk SSSR, vol. 102, no. 4, p. 711, 1955, [in Russian].

[45] B. Z. Katsenelenbaum, "On the general theory of irregular waveguides [K obshchej teorii neregulyarnyh volnovodov]," Russian, Doklady Akademii Nauk SSSR, vol. 116, no. 2, pp. 203-206, 1957, [in Russian].

[46] A. G. Sveshnikov, "An approximate method for calculating a weakly irregular waveguide [Priblizhennyj metod rascheta slabo neregulyarnogo volnovoda]," Russian, Doklady Akademii Nauk SSSR, vol. 110, no. 2, pp. 197-199, 1956, [in Russian].

[47] G. Y. Lyubarsky and A. Y. Povzner, "On the theory of wave propagation in irregular waveguides [K teorii rasprostraneniya voln v neregulyarnyh volnovodah]," Russian, Zhurnal tekhnicheskoy fiziki, no. 29, pp. 170-179, 1959, [in Russian]. 
[48] N. E. Maltsev, "Some modifications of the method of cross sections [Nekotorye modifikacii metoda poperechnyh sechenij]," Russian, Akusticheskii zhurnal, no. 16, pp. 102-109, 1970, [in Russian].

[49] B. Z. Katsenelenbaum, "Curved waveguides of constant cross-section [Izognutye volnovody postoyannogo secheniya]," Russian, Radiotekhnika i elektronika, no. 2, pp. 171-185, 1956, [in Russian].

[50] B. Z. Katsenelenbaum, "Symmetric dielectric transition in a circular waveguide for the $H_{01}$ wave [Simmetrichnyj dielektricheskij perekhod v volnovode kruglogo secheniya dlya volny $H_{01}$ ]," Russian, Radiotekhnika i elektronika, no. 3, p. 339, 1956, [in Russian].

[51] B. Z. Katsenelenbaum, "Long symmetric waveguide transition for the $H_{01}$ wave [Dlinnyj simmetrichnyj volnovodnyj perekhod dlya volny $H_{01}$ ]," Russian, Radiotekhnika i elektronika, no. 5, pp. 531-546, 1957, [in Russian].

[52] A. G. Sveshnikov, "On the propagation of radio waves in weakly curved waveguides [O rasprostranenii radiovoln v slaboizognutyh volnovodah]," Russian, Radiotekhnika i elektronika, vol. 1, no. 9, p. 1222, 1956, [in Russian].

[53] A. G. Sveshnikov, "Waves in curved pipes [Volny v izognutyh trubah]," Russian, Radiotekhnika i elektronika, vol. 3, no. 5, p. 641, 1958, [in Russian].

[54] A. G. Sveshnikov, "Irregular waveguides [Neregulyarnye volnovody]," Russian, Izv. Vuzov. Radiofizika, vol. 2, no. 5, p. 720, 1959, [in Russian].

[55] A. G. Sveshnikov, "An approximate method for calculating a weakly irregular waveguide [Priblizhennyj metod rascheta slabo neregulyarnogo volnovoda]," Russian, Doklady Akademii Nauk SSSR, vol. 80, no. 3, pp. 345-347, 1956, [in Russian].

[56] A. G. Sveshnikov, "On the proof of a method of calculation for irregular waveguides," USSR Computational Mathematics and Mathematical Physics, vol. 3, no. 1, pp. 219-232, 1963.

[57] A. G. Sveshnikov, "A substantiation of a method for computing the propagation of electromagnetic oscillations in irregular waveguides," USSR Computational Mathematics and Mathematical Physics, vol. 3, no. 2, pp. 413-429, 1963. DOI: 10.1016/0041-5553(63)90027-2.

[58] A. G. Sveshnikov, "On the bending of waveguides," USSR Computational Mathematics and Mathematical Physics, vol. 1, no. 3, pp. 882-888, 1962.

[59] A. G. Sveshnikov and A. S. Il'inskii, "Calculation of waveguide transition of composite form," USSR Computational Mathematics and Mathematical Physics, vol. 3, no. 3, pp. 635-649, 1963.

[60] A. S. Il'inskii and A. G. Sveshnikov, "Methods for investigating irregular waveguides," USSR Computational Mathematics and Mathematical Physics, vol. 8, no. 2, pp. 167-180, 1968. 
[61] A. G. Sveshnikov, "The incomplete Galerkin method [Nepolnyj metod Galerkina]," Russian, Dokl. Akad. Nauk SSSR, vol. 236, no. 5, pp. 1076 1079, 1977, [in Russian].

[62] A. N. Bogolyubov and A. G. Sveshnikov, "Application of an iteration method to the investigation of plane waveguides with inhomogeneous filling," USSR Computational Mathematics and Mathematical Physics, vol. 14, no. 4, pp. 125-133, 1974.

[63] A. N. Bogolyubov and A. G. Sveshnikov, "Justification of a finite-difference method for analyzing optical waveguides," USSR Computational Mathematics and Mathematical Physics, vol. 19, no. 6, pp. 139-150, 1979.

[64] A. N. Bogolyubov, A. L. Delitsyn, and A. G. Sveshnikov, "On the problem of excitation of a waveguide filled with an inhomogeneous medium," Computations mathematics and mathematical physics, vol. 39, no. 11, pp. 1794-1813, 1999.

[65] A. N. Bogolyubov and M. D. Malykh, "Remark on the Radiation Conditions for an Irregular Waveguide," Computations mathematics and mathematical physics, vol. 43, no. 4, pp. 560-563, 2003.

[66] A. N. Bogolyubov and M. D. Malykh, "Theory of Perturbations of Spectral Characteristics of Waveguide Systems," Computations mathematics and mathematical physics, vol. 43, no. 7, pp. 1049-1061, 2003.

\section{For citation:}

A.L. Sevastianov, Single-mode propagation of adiabatic guided modes in smoothly irregular integral optical waveguides, Discrete and Continuous Models and Applied Computational Science 28 (4) (2020) 361-377. DOI: 10.22363/2658-4670-2020-28-4-361-377.

\section{Information about the authors:}

Sevastianov, Anton L. - Candidate of Physical and Mathematical Sciences, assistant professor of Department of Applied Probability and Informatics of Peoples' Friendship University of Russia (RUDN University) (e-mail: sevastianov-ale rudn.ru, ORCID: https://orcid.org/0000-0002-0280-485X, Scopus Author ID: 50462435500) 
DOI: $10.22363 / 2658-4670-2020-28-4-361-377$

\title{
Одномодовый режим распространения адиабатических волноводных мод плавно-нерегулярных интегрально-оптических волноводов
}

\author{
А. Л. Севастьянов \\ Российский университет дружбы народов \\ ул. Миклухо-Маклал, д. 6, Москва, 117198, Россия
}

В работе представлено исследование волноводного распространения поляризованного электромагнитного излучения в тонкоплёночном интегральнооптическом волноводе. Для описания этого распространения используется адиабатическое приближение решений уравнений Максвелла. Построение редуцированной модели для адиабатических волноводных мод, сохраняющей все свойства соответствующих приближённых решений системы уравнений Максвелла, было проведено автором в предыдущей публикации в DCM\&ACS, 2020, № 3. В настоящей работе исследование проведено для частного случая, когда геометрия волновода и электромагнитное поле инвариантны в поперечном направлении. В этих условиях существуют раздельные нетривиальные ТЕи ТМ-поляризованные решения указанной редуцированной модели. В работе описываются параметрически зависящие от продольных координат решения задач на собственные значения и собственные функции - адиабатические волноводные ТЕ- и ТМ-поляризации. В работе приводится постановка задачи отыскания решений модели адиабатических волноводных мод, описывающих стационарное распространение электромагнитного излучения. Представлены решения для одномодового распространения ТЕ- и ТМ-поляризованных адиабатических волноводных волн.

Ключевые слова: волноводное распространение поляризованного света, интегральный оптический волновод, адиабатическое приближение, собственные значения и собственные функции, метод Канторовича, одномодовый режим 